\title{
Van - Hakkâri Yörelerinde \\ Sine Olarak Bilinen Kilimler
}

\section{Ela TAŞ*}

\section{ÖZET}

İnsanoğlu ihtiyaçlarını karşılamak ve kendilerini soğuktan korumak gibi nedenlerden dolayı dokumalar üretmişlerdir. Bilindiği gibi dokumalar, düz ve havlı dokumalar olmak üzere iki gruba ayrılmaktadırlar. Düz dokumalar da dokunuş tekniklerinden dolayı kilim, cicim, zili, sumak olmak üzere dört gruba ayrılmaktadırlar. Bu düz dokumalar içerisinde de kilimler önemli bir grubu oluşturmaktadır. Kilimler isimlerini bölge, aşiret ve üzerinde kullanılan motiflerden almaktadır.

Sine kilimleri de adını İran'ın Senah bölgesinden alan kilimlerdir ve bu kilimler, Van Hakkâri yörelerinde de dokunmaktadırlar. Bu makalede Sine Kilimleri kullanılan teknik, malzeme, renk, motif ve kullanılan kompozisyon özelliklerine göre tanıtılmaktadır.

Anahtar Kelimeler: Dokuma, İran, Van, Hakkâri, Kilim, Sine.

\section{Giriş}

Düğümlü halı dışında kalan, iki veya daha çok iplik grubunun birbirlerinin arasından değişik şekillerde geçirilmesiyle ortaya çıarılan yaygı türleri düz dokuma olarak tanımlanmaktadır. Düz dokumalar yapılış tekniklerindeki farklılıklardan dolayı kilim, cicim, zili, sumak gibi çeşitli gruplara ayrılmakta bunların büyük bir kısmını kilimler oluşturmaktadır.

Yrd. Doç. Dr., Yüzüncü Yıl Üniversitesi, Edebiyat Fakültesi, Sanat Tarihi Bölümü, 65080 - Kampus/ Van, e-posta: elaatas@gmail.com

1 B. Balpınar Acar, Kilim, Cicim, Zili, Sumak Türk Düz Dokuma Yaygıları, İstanbul, 1982, s. 7.

\section{Kilims Known as Sehna}

in the Regions of Van - Hakkari

\section{ABSTRACT}

Humanbeing produced weavings to protect himself from cold and to satisfy his needs. The flat weaves, as it is known, are the kinds of ground clothes which are different from towel weavings. They are revealed in lenght and breadth, two or more groups of thread are passed over differently among themselves and they are named as kilim, cicim, zili and sumak. Kilim is the most common smooth weaving product among smooth weavings. Kilims take their names according to the region, tribe and motifs.

This paper introduces Sine kilims which are named after Senendaj the city of Persia and are woven in the region of Van - Hakkâri and analyzes them in terms of type, material, color, motives and ways of composition.

Keywords: Weaving, Persia, Van, Hakkâri, Kilim, Sehna.

Kilimler, iki iplik sistemine dayanılarak yapılan, tersi ve düzü birbirinin benzeri olan dokumalardır². Bu çalışmada iki iplik sistemine dayanılarak yapılan Sine Kilimleri tanıtılmaktadır.

Dokumacılık yönünden köklü bir geçmişe sahip olan Van ve Hakkâri yörelerinde kilim dokumacıllğının önemli bir yeri olduğu bilinmektedir. Bunun başlıca sebebi hayvancılığın bu yörelerde ana geçim kaynağını oluşturmasıdır. Bu yörelerde yaşayan insanlar yetiştirdikleri hayvanların yünlerinden ip elde etmekte, bunları doğal boyalarla renklendirmekte ve üretecekleri

2 F. P. Akbil, Türk El Sanatlarından Örnekler, 1970, s. 9. 
dokumalarda kullanmaktadır. Dokumayı üreten aşirete ya da üzerinde kullanılan motife göre adlandırılan kilimlerin bir grubunu da Sineler oluşturmaktadır.

Dokumacılıkta genel olarak bir düğüm ${ }^{3}$ çeşidi olarak bilinen Sine aslında Batı İran'da yer alan Senandaj ${ }^{4}$ Bölgesi'ne verilen isimdir ve burada ortaya konan bir grup dokumada Sine olarak anılmaktadır. Senandaj'da ortaya konan Sineler, Van - Hakkâri yörelerinde de dokunmaktadır. Bunun başlıca sebebi bu iki şehrin, İran'la sınır komşusu olmaları ve bunun sonucunda da ülkeler arasında kültürel etkileşimin gerçekleşmesidir. Bu etkileşimle birlikte bu yörelerde ortaya konan bu türde dokumalar "Van Sinesi" ya da "Hakkâri Sinesi" olarak adlandırılmaktadır.

Sineler, havsız yaygılardır ve iki iplik sistemine dayanılarak yapıldığından düz dokumalar grubuna girmektedir. Oldukça karmaşık süslemelere sahip olan Sineler, teknik ve kompozisyon gibi açılardan yüksek bir seviye gösterdiğinden dünya çapında haklı bir üne sahiptir 5 .

Sine dokumalar; dikey tezgâhlarda, tek parça olarak meydana getirilmekte, büyük tasarlanmakta, ilikli, iliksiz ve eğri atkılı kilim teknikleriyle ortaya konmaktadırlar. Sinelerin çözgülerini ve atkılarını genel olarak yün iplik oluşturmaktadır ${ }^{6}$. Ancak çözgüsü yün - atkısı ipek, çözgüsü pamuk - atkısı yün ya da çözgüsü ve atkısı ipek olan örnekleri de mevcuttur. Bunların yanı sıra son zamanlarda yapılan örneklerde orlon iplerin de kullanıldığı görülmektedir.

Bu kilimlerin yapımında kullanılan iplerin, geçmişte tamamen bitkilerden elde edilen doğal boyalarla boyandığı, günümüzde ise renk zenginliğini arttırmak ve bitkilerden renk elde etmenin zahmetli olmasından dolayı anilin boyalardan da yararlanıldı ̆̆ı bilinmektedir. Ağılıklı olarak kırmızı, lacivert, siyah, beyaz renklerin kullanıldığı, dokumaya hareketlilik, estetik bir görünüm kazandırmak ve yöresel alışkanlıklar gibi nedenlerden sarı, pembe ve mavi renklere de yer verildiği gözlenmektedir.

3 Sine düğümünde, düğüm ipliği yalnız bir çözgüye sarılmakta, diğer ucu ise sarılmadan yandaki çözgünün arkasından üste çıkarılmaktadır. Bu düğüm genel olarak İran, Türkistan, Hindistan ve Çin'de yapılan halılarda kullanılmaktadır. Bu ülkelerin yanı sıra Türkiye'de yapılan bazı halılarda da kullanıldığı bilinmektedir. Ancak bu düğüm çeşidi, hav ipinin bir ucunun serbest bırakılmasından dolayı pek sağlam değildir. Geniş bilgi için bkz. Ç. Aytaç, El Dokumacilığı, İstanbul, 1982, s. 135,136.

41935 yılına kadar Persia olarak adlandırılan ülke, birçok uygarlık tarafından halı ve kilimlerin başlıca dokuma merkezi olarak kabul edilmekteydi. Çeşitli medeniyetleri bünyesinde barındırmış olan bu ülke, özellikle Safevi egemenliği altındayken sanatsal ve kültürel alanda o güne kadar görülmemiş başarılara imza atmış ve İran dokuma ve tekstil merkezi haline getirilmiştir. Ülke sınırlarında dokuma faaliyetleri özellikle göçebeler ve kabileler tarafından yürütülmektedir. Bunların yanı sıra atölyelerde de sınırlı sayıda dokuma üretiminin yapıldığı bilinmektedir. İran'da yaşayan göçebeler tarafından yapılan dokumalar, dokumacılıkla uğraşan diğer ülkelerde ortaya konan dokumalardan daha farklı olup, motif yönünden zengindir. Geniş bilgi için bkz. L. Allane, Kilims A Buyer's Guide, London, 1995, pp. $110-112$.

5 L. Kerimov, Azerbaijan Carpet, Azerbaijan, 1983, p. 258

6 J. Franses, Europen and Oriental Rugs, London, 1970, p. 111
Desenin oluşturulmasında fazla itina ve dikkat isteyen Sineler, genel olarak merkezi kompozisyonlu olarak tasarlansa da serpme kompozisyonlu örnekleri de mevcuttur ${ }^{7}$. Bu dokumaların kompozisyon düzenleri merkezde yer alan madalyon ya da madalyonlar çevresinde gelişme göstermektedir. Sineler ya tek madalyonlu olarak ya da iç içe geçmiş iki ya da daha fazla madalyonun kombinasyonundan oluşmaktadır. Madalyonların içleri de çeşitli hayvan figürleri, geometrik şekiller ya da stilize edilmiş bitkisel motiflerle doldurularak zenginleştirilmektedir.

İncelemiş olduğumuz kaynaklarda, Sine dokumalarında Boteh ve Herat $^{8}$ olarak adlandırılan motiflerin kullanıldığı belirtilmektedir.. Boteh, gözyaşı ya da yaprağ ${ }^{9}$ andıran forma sahiptir ve Persçe'de "Yaprak Demeti" şeklinde tanımlanmaktadır. Bunun yanı sıra uzmanlar, Sine kilimlerinde yer alan ana motifin; kozalak, selvi ağacı, yaprak, ya da Zerdüşt Ateşi'ni simgelediğini de belirtmektedir. Herat ise; adını Afganistan'ın Herat şehrinden almıştır. Bu motif, elması andıran bir çiçeği, dört taraftan saran yapraklardan oluşmaktadır. Bu motif mahi (Farsça'da balık) ya da göldeki balık isimleriyle de anılmakta ve Pers mitolojisinde yüzen dört balıkla desteklenmektedir. İran'ın Ferahan kasabasında yapılan dokumalarda sık kullanılmasından dolayı Ferahan motifi olarak da tanımlanmaktadır. Çok yüklü anlamalara sahip olsa da biçim olarak aynı şekilde dokumalarda yer almak$\operatorname{tad}^{\prime 1}{ }^{10}$. İncelemiş olduğumuz 8 numaralı resimde görülen örnek bu motiflere sahiptir.

Van - Hakkâri yörelerinde de Sinelerin, ana motifinin balık ${ }^{11}$ olduğu kaynak kişilerle yapılan görüşmelerde elde edilen bilgilerden ${ }^{12}$ olsa da ele aldığımız örneklerde balık motifi karşımıza çıkmamıştır. Bu motifin yerine madalyon, semaver, uğur böceği, insan hayvan (kuş, ördek, keçi) figürleri ya da stilize edilmiş bitkisel motiflerin kullanıldığı ve dokumalarında kullanılan bu motiflere göre adlandırıldığı görülmektedir ${ }^{13}$.

$\mathrm{Bu}$ çalışmada incelenen Sine Kilimleri'nin; teknik, malzeme, boya, kompozisyon düzenleri ve motifleri şu şekildedir:

\footnotetext{
Kilim kompozisyonları hakkında geniş bilgi için bkz. Recai Karahan, Konya Müzelerinde Bulunan Kilimler, Selçuk Üniversitesi Sosyal Bilimler Enstitüsü Basılmamış Doktora Tezi, Konya, 1992, s. 384,385 .

8 Lee Allane, Oriental Rugs A Buyer's Guide, London, 1992, p. 88.

9 Lee Allane, Rugs, p. 124

10 Lee Allane, Rugs, pp. 88, 89.

11 Uzun bir geçmişe sahip olan balık motifi Hristiyan olan ve olmayan ülkelerde yüzlerce yıldır kullanılagelen bir motiftir. Bu motifin verimliliği, doğurganlığı arttırdığına, yaşamın yenilenmesini sağladı̆̆ına, refah getirdiğine ve büyülerden koruduğuna inanılmaktadır. Geniş bilgi için bkz. D. Morris, Body Guards, England, 1999, p. 17

12 Bu bilgi Tahir Aslan'dan 15.06.2010 tarihinde yapılan görüşmede öğrenilmiştir.

13 Bu bilgi Sayın Hamza Acar'dan 22.06.2010 tarihinde yapılan görüşmede elde edilmiştir
} 


\section{2. ÖRNEKLER}

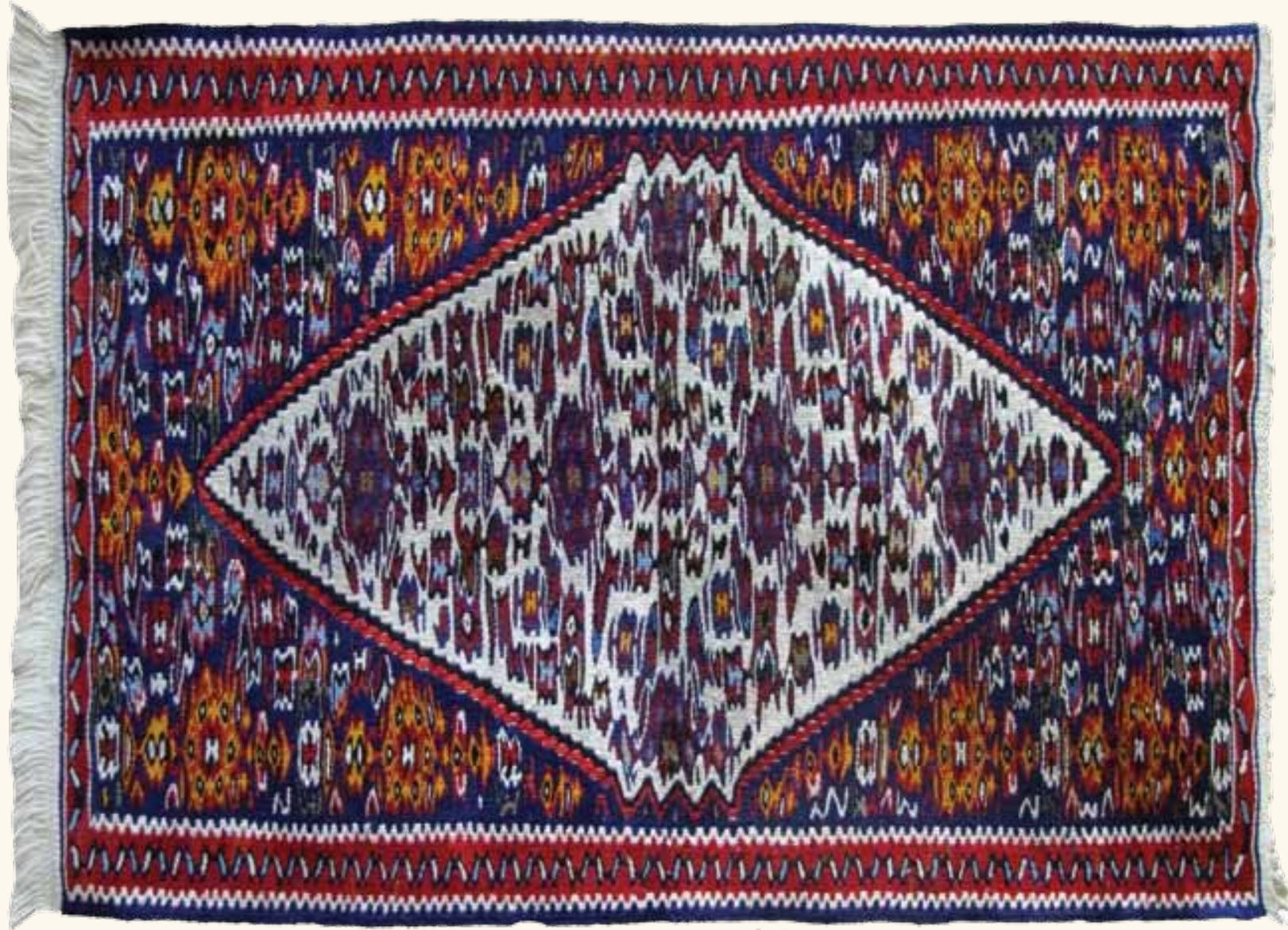

Resim 1

Resim no: 1

Çizim no: 1

Adı: Semaverli Sine

Yöresi: Van - Hakkâri

Cinsi: Divan Kilimi

En: $67 \mathrm{~cm}$

Boy: $110 \mathrm{~cm}$.

Teknik: İlikli ve Eğri Atkılı Kilim Teknikleri

\section{Malzeme:}

Çözgü: Yün

Atkı: Yün

Boya: Bitkisel

Kompozisyon: 67 x $110 \mathrm{~cm}$. ebatlarında yapılmış tek parçadan oluşan divan kilimidir. Çözgü ve atkı iplikleri yündür. İpler bitkilerden elde edilen doğal boyalarla boyanmıştır. İlikli ve eğri atkılı kilim tekniklerinin bir arada kullanıldığı örnek merkezi kompozisyonlu kilimler grubundadır.

Lacivert zeminli kilimin merkezinde kırmızı renklerle konturlanmış beyaz zeminli madalyon motifi yer almaktadır. Madalyonun içi birliği, bir arada olmayı simgeleyen semaver motifinin kaydırılmış eksenler üzerine yerleştirilmesiyle doldurulmuştur. Madalyonun dışında kalan alanlarda da aynı motifin işlendiği görülmektedir. Bu motifin yanı sıra stilize edilmiş şekiller de dokuma zeminini zenginleştirmektedir.

Zemin ve bordür temizliği simgeleyen tarak motifleriyle sınırlandırılmıştır. Dokuma zeminini kırmızı renkli bordürler çevrelemektedir ve içi hayatın akıcılığını simgeleyen suyolu motifi kullanılmıştır. 


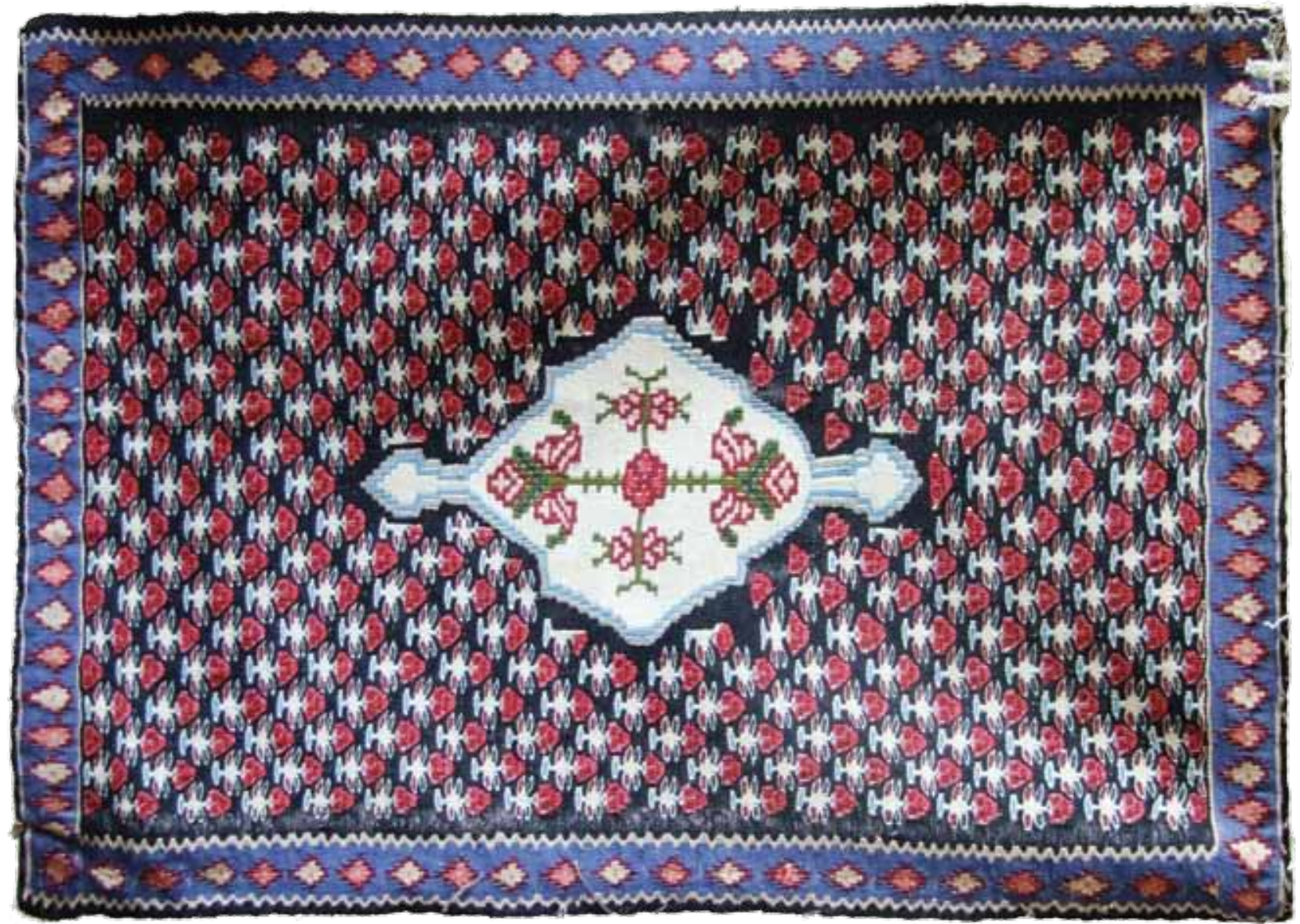

Resim 2

\section{Resim no: 2}

Çizim no: $4,5,8$

Adı: Çiçekli Sine

Yöresi: Van - Hakkâri

Cinsi: Taban Kilimi

En: $70 \mathrm{~cm}$.

Boy: $104 \mathrm{~cm}$.

Teknik: İliksiz ve Eğri Atkılı Kilim Teknikleri

\section{Malzeme:}

Çözgü: Pamuk

Atkı: Yün, Süsleme amaçlı olarak sime de yer verilmiştir.

Boya: Bitkisel ve anilin

Kompozisyon: 70 x $104 \mathrm{~cm}$. ebatlarında dokunmuş taban kilimidir. Tek parça olarak yapılan dokumanın çözgü ipi pamuk, atkı ipi ise yündür. İpler bitkisel ve anilin boyalarla boyanmıştır. İliksiz ve eğri atkılı kilim tekniklerinin bir arada kullanıldığı örnek merkezi kompozisyonludur.

Siyah zeminli dokumanın merkezinde gri ve mavi renklerle çevrelenmiş beyaz zeminli madalyon yer almaktadır ve içi bitkisel desenlerle bezenmiştir.

Madalyonun uç kısımları salbeklerle uzatılmıştır. Madalyonun dışında kalan kısımlarda çiçek motiflerinin kaydırılmış eksenler üzerine işlenmesiyle doldurulmuştur.

Zemin ve bordür hayatın devamlılığını simgeleyen zig zag motifleriyle sınırlandırılmıştır. Mavi zeminli bordür dokumayı çevrelemektedir ve içi nazarı uzaklaştırmak amacıyla kullanılan göz motifleriyle dolgulanmıştır.

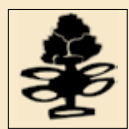

Çizim 4. Çiçek

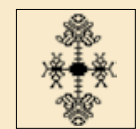

Cizim 5

Çiçek Demeti (Herat)

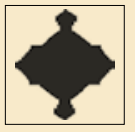

Çizim 8. Madalyon 


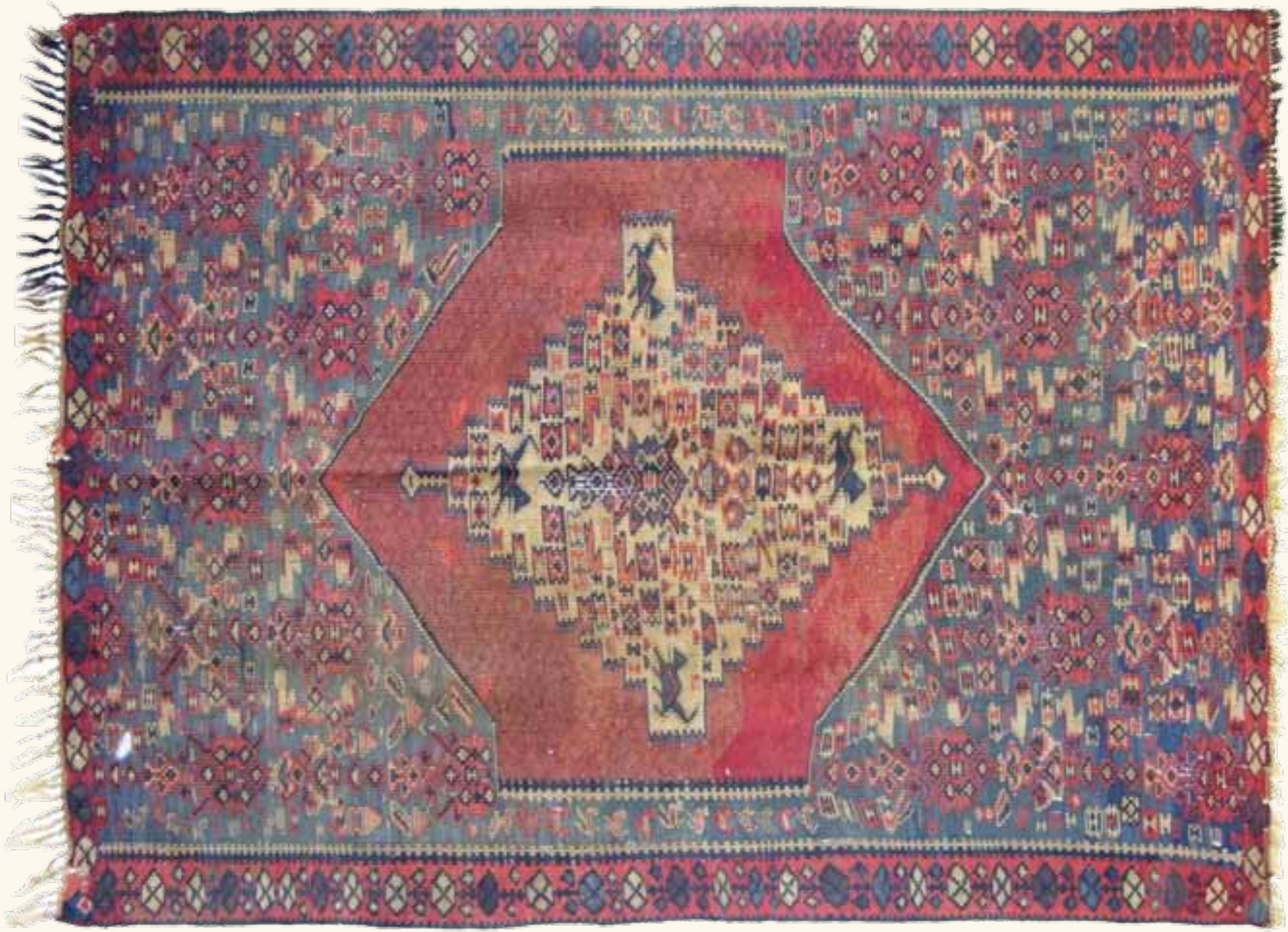

Resim 3.

\section{Resim no: 3}

Çizim no: 2, 3, 9, 11, 12

Adı: Elibelindeli Sine

Yöresi: Van- Hakkâri

Cinsi: Taban Kilimi

En: $141 \mathrm{~cm}$.

Boy: $202 \mathrm{~cm}$.

Teknik: İlikli kilim

Malzeme:

\section{Çözgü: Yün}

Atkı: Yün

Boya: Bitkisel

Kompozisyon: $141 \times 202 \mathrm{~cm}$ ebatlarında taban kilimidir. Tek parçadan oluşan dokuma oldukça büyük tasarlanmıştır. Çözgü ve atkı ipleri yün malzemeli olup bitkisel boyalardan elde edilen renkler kullanılmıştır. İlikli kilim tekniğiyle yapılmış örnek merkezi kompozisyonlu kilimler grubundadır.

Lacivert zeminli dokumanın merkezinde iç içe yerleştirilmiş iki madalyona yer verilmiştir. İç kısımda yer alan madalyon beyaz zeminli olup insan, hay- van ve geometrik şekillerle doldurulmuştur. Kırmızı zeminli olarak yapılmış madalyonda ise motife yer verilmemiştir. Madalyonların dışında kalan kısımlar ise mavi zeminlidir ve iç madalyonda yer alan insan figürleriyle doldurulmuştur.

Kırmızı zeminli bordür çeşitli renklerle yapılmış ve nazarı uzaklaştırmak amacıyla kullanılan göz motifleriyle bezenmiştir.
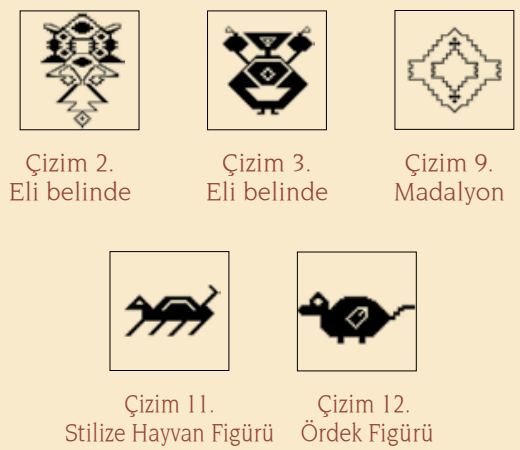


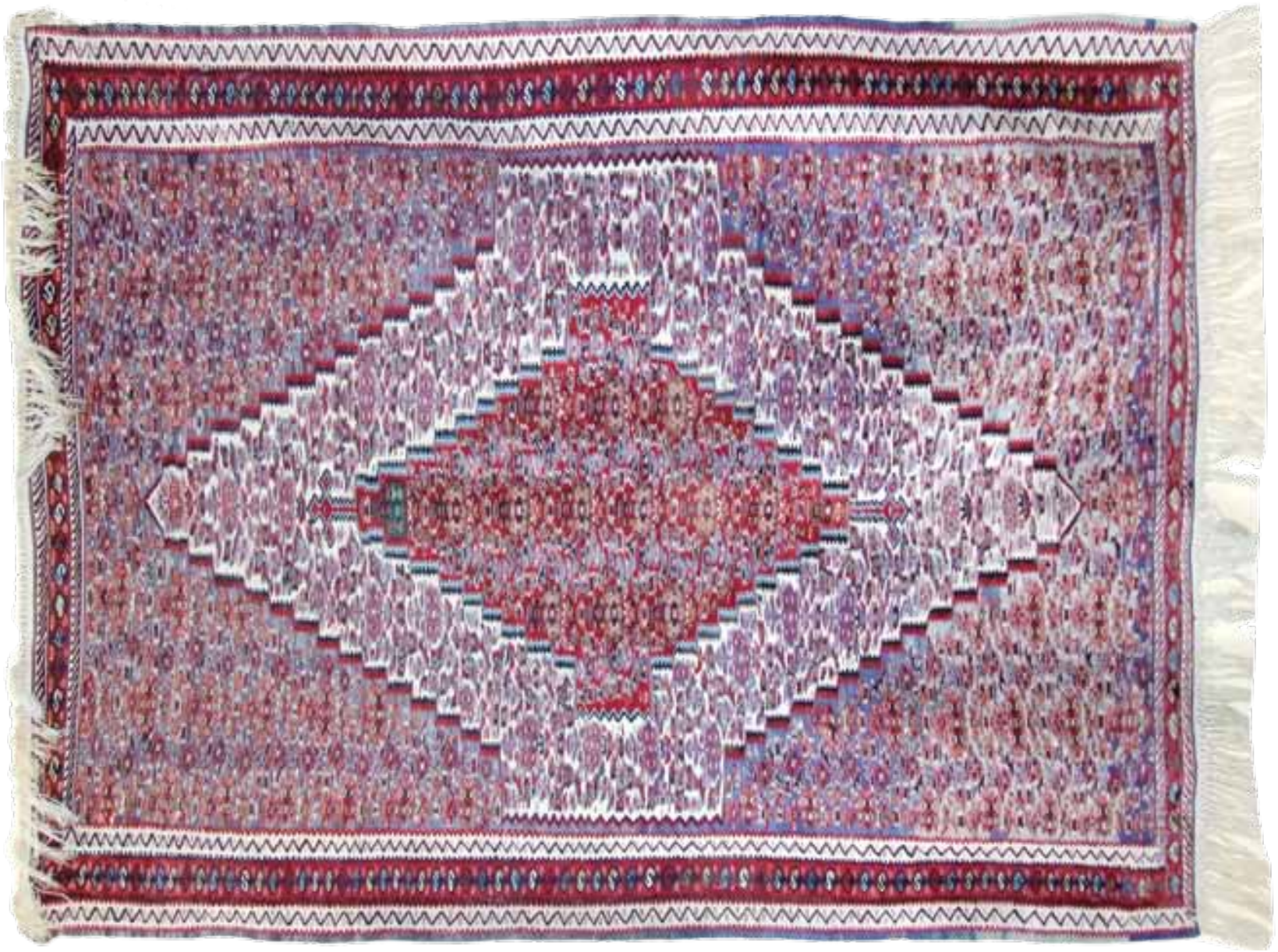

Resim 4

\section{Resim no: 4}

Çizim no: 1,9

Adı: Semaverli Sine

Yöresi: Van - Hakkâri

Cinsi: Taban Kilimi

En: $144 \mathrm{~cm}$

Boy: $202 \mathrm{~cm}$.

Teknik: İliksiz Kilim Tekniği

\section{Malzeme:}

Çözgü: Yün

Atkı: Yün

Boya: Bitkisel

Kompozisyon: 144 x 202 cm. ebatlarına sahip taban kilimidir. Tek parça olarak yapılmış dokumanın malzemesi yün iptir ve bunlar bitkilerden elde edilen doğal boyalarla renklendirilmiştir. İliksiz kilim tekniğiyle yapılan örnek merkezi kompozisyonlu kilimler grubundadir.

Açık mavi zeminli dokumanın merkezinde iç içe geçmiş, kırmızı ve beyaz zeminli olarak tasarlanmış iki madalyon yer almaktadır. Bunların içlerinde se-

maver motiflerine yer verilmiştir. Madalyonların d1şında kalan kısımlarda da aynı motifin kaydırılmış eksenler üzerinde yerleştirildiği ve zeminin doldurulduğu görülmektedir.

Zemini üç bordür çevrelemektedir. Bunlardan ikisi beyaz zeminli olup dar tutulmuştur ve içleri hayatın akıcılığını simgeleyen suyolu motifleriyle dolgulanmıştır. Ortada bulunan bordür ise kırmızı zeminli olu daha geniştir. Bu da zıtlıkları simgeleyen çengel motifleriyle bezenmiştir.

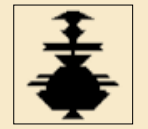

Çizim 1 . Semaver

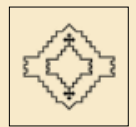

Çizim 9.

Madalyon 


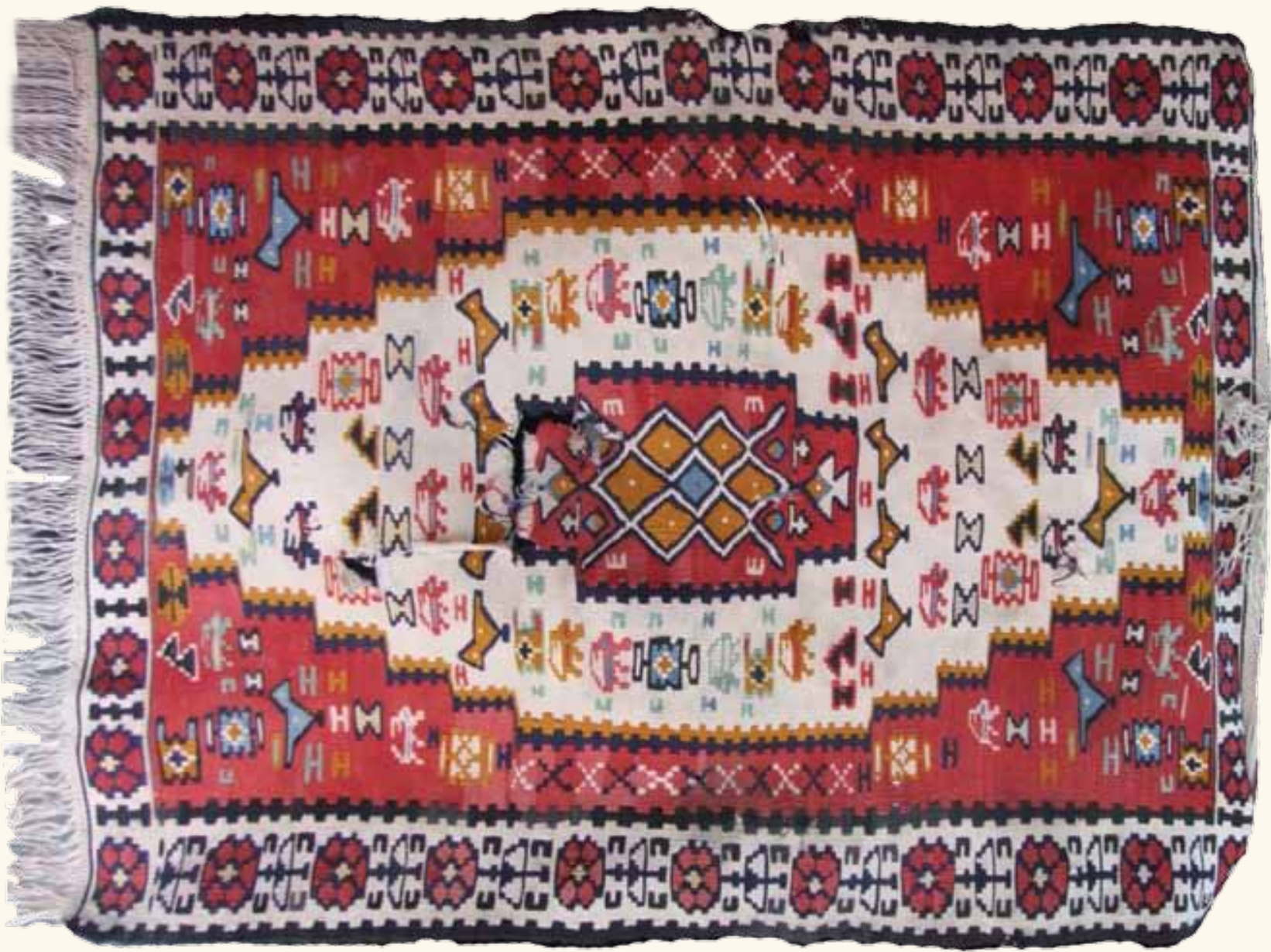

Resim 5

\section{Resim no: 5}

Çizim no: 6, 13, 14

Adı: Uğur Böcekli Sine

Yöresi: Van- Hakkâri

Cinsi: Divan Kilimi

En: $75 \mathrm{~cm}$

Boy: $116 \mathrm{~cm}$.

Teknik: İlikli Kilim

Malzeme:

Çözgü: Pamuk

Atkı: Yün

Boya: Bitkisel boya

Kompozisyon: 75 x $116 \mathrm{~cm}$. ebatlarında divan kilimidir. Dokumanın malzemesini yün ip oluşturmaktadır. İpler bitkilerden elde edilen doğal boyalarla renklendirilmiştir. İlikli kilim tekniğinde yapılan örnek merkezi kompozisyonlu dokumalar grubundadır.

Kırmızı zeminli dokumanın merkezinde, gelin kızın çeyizini simgeleyen ve sandık olarak adlandırılan kırmızı zeminli madalyon yer almaktadır. Bunun içi stilize edilerek yapılmış uğur böceği figürüyle dol-

gulanmıştır. Beyaz zeminli olarak tasarlanmış olan ikinci madalyon ise çevikliği, cinsel gücü simgeleyen keçi, haber beklentisini simgeleyen kuş figürleri, evlilik isteğini dile getiren küpe motifleriyle bezenmiştir. Madalyonların dişında kalan alanlarda da aynı motiflerin tekrarlandığı görülmektedir.

Zemin ve bordür tarak motifleriyle sınırlandırılmıştır. Beyaz zeminli olarak yapılmış bordür ise kırmızı ve siyah renklerle yapılan stilize edilmiş bitkisel motiflerle bezenmiştir.

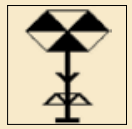

Çizim 6. Çiçek
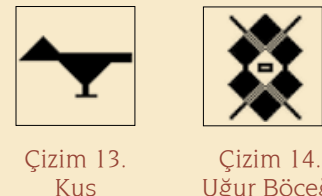

Çizim 14. Uğur Böceği 




Resim 6.

\section{Resim no: 6}

Çizim no: 7,10

Adı: Çiçekli Sine

Yöresi: Van - Hakkâri

Cinsi: Taban Kilimi

En: $156 \mathrm{~cm}$.

Boy: $205 \mathrm{~cm}$.

Teknik: İlikli Kilim Tekniği

Malzeme:

Çözgü: Yün

Atkı: Yün

Boya: Bitkisel ve anilin boya

Kompozisyon: 156 x 205 cm. ebatlarına sahip taban kilimidir. Dokumanın atkı ve çözgü ipleri yündür. İpler, bitkilerden elde edilen doğal boyalar ve anilin boyalarla renklendirilmiştir. İlikli kilim tekniğiyle yapılan dokuma merkezi kompozisyonlu kilimler grubundadır.

Zemin iç içe geçmiş madalyonlardan oluşmaktadır. En içte kalan mavi, ortadaki kırmızı ve üçüncü madalyon ise beyaz zemine sahiptir. Madalyonların dışında kalan kısımlar siyah zeminli olarak tasarlanmıştır. Tüm dokuma yüzeyi kaydırılmış eksenler şeklinde işlenmiş çiçek motifleriyle doldurulmuştur.

Zemini, içleri nazardan korunmak amaciyla kullanılan göz motifli, mavi zeminli bordürler çevrelemektedir. Dokuma saçaklarla son bulmaktadır.

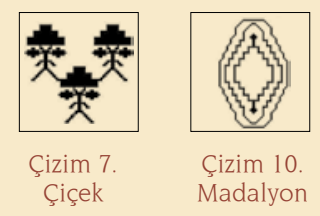




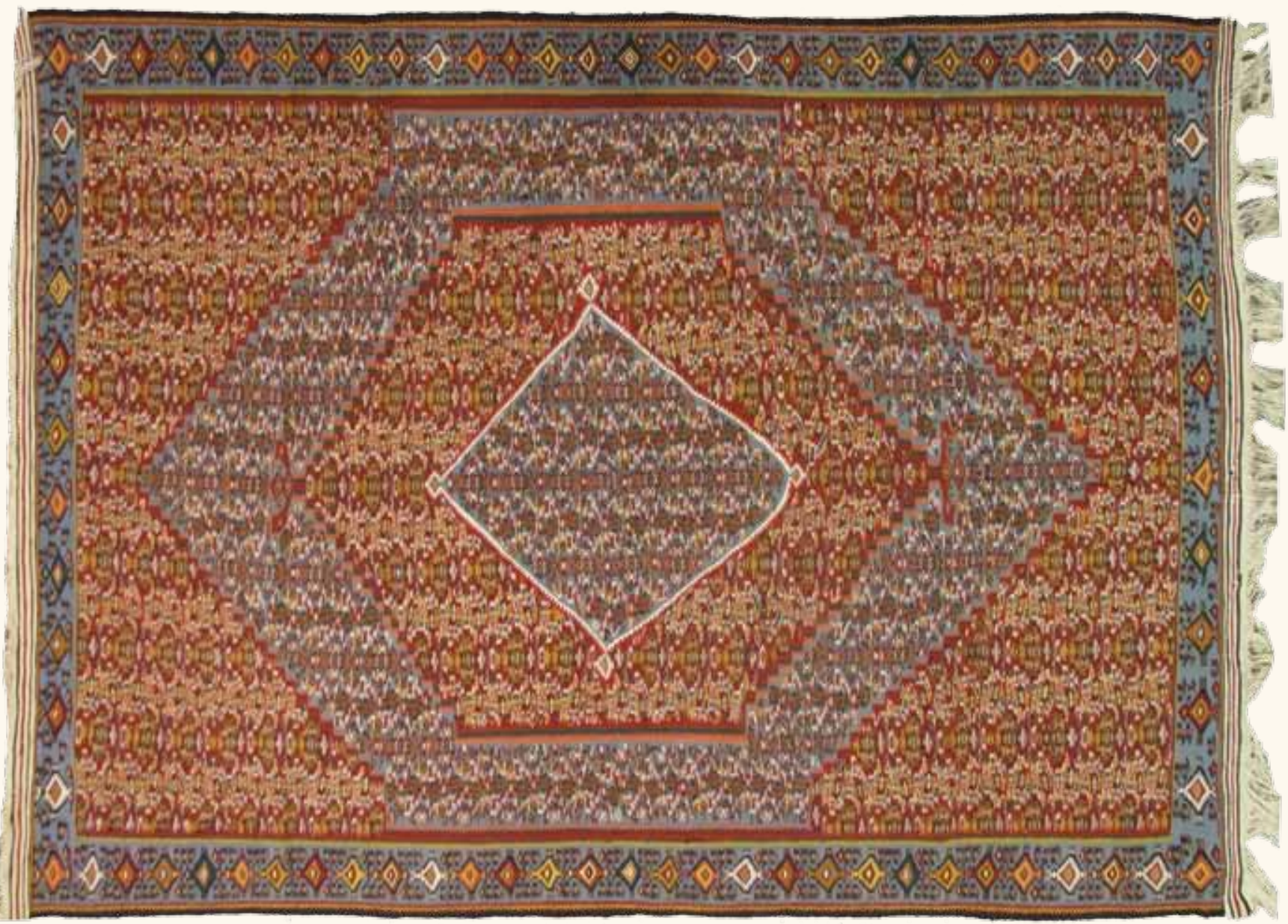

Resim 7

\section{Resim no: 7}

Çizim no: 1,9

Adı: Semaverli Sine

Yöresi: Van - Hakkâri

Cinsi: Taban Kilimi

En: $158 \mathrm{~cm}$.

Boy: $210 \mathrm{~cm}$.

Teknik: İlikli Kilim Tekniği

Malzeme:

\section{Çözgü: Yün}

Atkı: Yün

Boya: Bitkisel boya

Kompozisyon: 158 x $210 \mathrm{~cm}$. ebatlarına sahip taban kilimidir. Atkı ve çözgü ipleri yündür. İpler doğal boyalarla renklendirilmiştir. İlikli kilim tekniğiyle yapılan örnek merkezi kompozisyonlu kilimler grubundadir.

Kırmızı ve mavi renklere sahip zemin, iç içe yerleştirilmiş madalyon motifleriyle hareketlendirilmiştir. En içte beyaz renkle konturlanmış mavi zeminli madalyon, ortada kırmızı zeminli siyah konturlu

madalyon, dışta ise mavi zeminli kırmızı konturlu madalyon yer almaktadır. Madalyonlar ve bunların dışında kalan alanlar semaver motifleriyle dolgulanmiştır.

Dokumayı mavi zeminli ve semaver motifleriyle dolgulanmış bordürler çevrelemektedir.

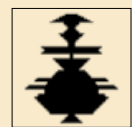

Cizim 1. Semaver

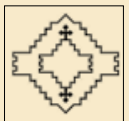

Çizim 9. Madalyon 


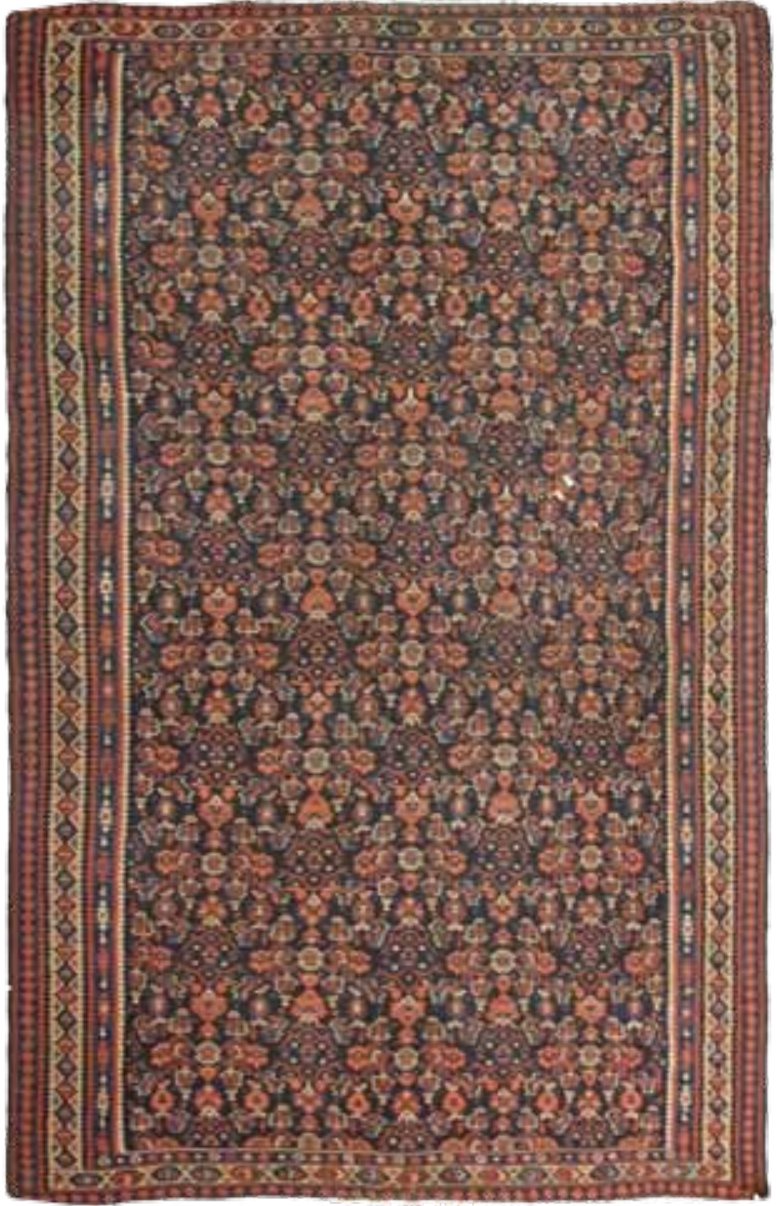

Resim 8 .

\section{Resim no: 8}

Adı: Sine

Yöresi: Van - Hakkâri

Cinsi: Taban Kilimi

En: $154 \mathrm{~cm}$.

Boy: $203 \mathrm{~cm}$.

Teknik: İlikli Kilim Tekniği

Malzeme:

Çözgü: Yün

Atkı: Yün

Boya: Bitkisel boya

Kompozisyon: 154 x 203 cm. ebatlarına sahip taban kilimidir. Oldukça büyük tasarlanmış dokuma tek parçadır. Atkı ve çözgü ipleri yündür. İpler bitkilerden elde edilen doğal boyalarla renklendirilmiştir. İlikli kilim tekniğiyle yapılan örnek serpme kompozisyonlu kilimler grubundadır.

Siyah zeminli dokumanın yüzeyi kırmızı, sarı ve mavi renkler kullanılarak yapılmış boteh ve herat olarak adlandırılan motiflerin kaydırılmış eksenler üzerinde yerleştirilmesiyle doldurulmuştur.

Dokumayı üç bordür çevrelemektedir ve bunlar nazardan korunmak amacıyla kullanılan göz motifleriyle bezenmiştir

\section{Sonuç}

Geçmişten günümüze ince bir zevkle meydana getirilen Anadolu dokumaları Dünya Dokuma Sanatı içinde önemli bir yere sahiptir.

Anadolu'da ortaya konan düz dokumaların her biri, dokumanın yapıldığı yörede yaşayan insanların kültürlerini yansıttığı için farklı kompozisyon ve motifleri üzerlerinde taşımaktadır.

Düz dokumalar içinde büyük payı, zengin motif içeriğine sahip olan ve yöreden yöreye farklı kompozisyon özellikleri gösteren kilimler oluşturmaktadır.

Anadolu'da önemli dokuma merkezleri arasında yer alan Van ve Hakkâri yörelerinde de farklı kompozisyon ve motiflere sahip kilimler üretilmektedir. $\mathrm{Bu}$ illerin dokuma alanında ileri bir seviyede olmalarının önde gelen sebebi birçok uygarlık tarafından başlıca dokuma merkezi olarak kabul edilen İran’la komşu olmalarıdır. Bu komşuluğun sonucu olarak gerçekleşen kültürel etkileşim birçok alanda olduğu gibi dokumacılık alanında da kendini göstermekte ve İran'ın Senandaj (Sine) şehrinde dokunan Sine Kilimleri bu yörelerde de dokunmakta, Van Sinesi ve Hakkâri Sinesi olarak adlandırılmaktadırlar.

Yapımında yün, pamuk ya da ipekten üretilen, doğal ya da anilin boyalarla renklendirilen iplerin kullanıldığı ilikli, iliksiz, eğri atkılı kilim teknikleriyle yapılan ve oldukça karmaşık bir düzene sahip olan Sineler genel olarak merkezi kompozisyona sahiptirler ve merkezde yer alan madalyon ve bunun etrafına yerleştirilen farklı motiflerden oluşmaktadırlar.

Kompozisyonları ve taşıdıkları motifler nedeniyle Anadolu kilimlerinden ayrılan bu dokumaların orijinal hallerinin korunarak dokunması ve dünya pazarlarına sunulması; bu yörelerin tanıtılmasını, kilim satışlarının artmasını ve Van - Hakkâri illerinde yaşayan insanlara önemli bir geçim kaynağı oluşturacağı kanaatindeyiz.

\section{Kaynaklar}

Acar, Belkıs Balpınar (1982), Kilim, Cicim, Zili, Sumak Türk Düz Dokuma Yayglları, İstanbul.

Akbil, Fatma Pamir (1970), Türk El Sanatlarindan Örnekler. Allane, Lee (1995), Kilims A Buyer's Guide, London.

Allane, Lee (1992), Oriental Rugs A Buyer's Guide, London. Aytaç, Çetin (1982), El Dokumacıllğı, İstanbul.

Franses, Jack (1970), Europen and Oriental Rugs, London.

Karahan, Recai (1992), Konya Müzelerinde Bulunan Kilimler, Selçuk Üniversitesi Sosyal Bilimler Enstitüsü Basılmamış Doktora Tezi, Konya, s. 384, 385.

Kerimov, Latif (1983), Azerbaijan Carpet, Azerbaijan.

Morris, Desmond (1999), Body Guards, England. 